\title{
NOTE ON TRANSGRIPTION
}

In the transcriptions I have tried to adhere to original spellings. In general $\mathrm{c} / \mathrm{t}$ and $\mathrm{v} / \mathrm{u}$ are modernised and Middle English thorn and yogh are written as th and $y$, but otherwise orthography is preserved. Abbreviation are expanded silently and punctuation kept to a minimum. When more than one manuscript is examined, variant readings which do not alter meaning are silently omitted. Biblical references in parentheses or brackets are an editorial addition, while biblical references made by the original scribe (particularly in Chapter 4) are presented as part of the text, keeping to the scribe's abbreviations. Biblical references follow the Chicago Manual of Style, with the four Latin Books of Kings divided into 1 and 2 Samuel and 1 and 2 Kings. The numbering of the Psalms follows the Gallican Psalter. Biblical quotations are from the 1969 edition of the Clementine Vulgate, while English translation follows the Douai-Rheims edition with Challoner Revisions. 
Eyal Poleg - 9781526110534

Downloaded from manchesterhive.com at 04/26/2023 12:55:10PM 